\title{
Evidence for genomic and nongenomic actions of estrogen in growth plate regulation in female and male rats at the onset of sexual maturation
}

\author{
B C J van der Eerden ${ }^{1}$, J Emons ${ }^{1}$, S Ahmed ${ }^{1}$, H W van Essen ${ }^{2}$, \\ C W G M Lowik ${ }^{3}$, J M Wit ${ }^{1}$ and $M$ Karperien ${ }^{1,3}$ \\ ${ }^{1}$ Department of Pediatrics, Leiden University Medical Center, Building 1, zone J6-S, PO Box 9600, 2300 RC Leiden, The Netherlands \\ ${ }^{2}$ Department of Endocrinology, Academic Hospital Free University, Amsterdam, The Netherlands \\ ${ }^{3}$ Department of Endocrinology and Metabolic Diseases, Leiden University Medical Center, Building 1, zone C4-R, PO Box 9600,2300 RC Leiden, \\ The Netherlands \\ (Requests for offprints should be addressed to M Karperien; Email: karperien@lumc.nl)
}

\begin{abstract}
Recently, both estrogen receptor (ER) $\alpha$ and $\beta$ were detected in growth plate chondrocytes of rats before sexual maturation, implying a role for estrogen at this stage. In this study, therefore, we investigated the effects of ovariectomy (OVX) or estrogen supplementation on parameters of longitudinal growth in 26-day-old rats, which were sexually immature at the start of the experiment. OVX caused an increase in body weight gain, tibial length and growth plate width due to an increased proliferating zone. This increase correlated with an increase in cell number, with a decrease in cell diameter and with increased proliferating cell nuclear antigen (PCNA) immunostaining compared with sham. Interestingly, the increase in proliferation was not caused by an increase in insulin-like growth factor-I (IGF-I) mRNA expression in the growth plate as assessed by real-time PCR. In contrast to OVX, $17 \beta$-estradiol $\left(\mathrm{E}_{2}\right)$ supplementation $(0.5 \mathrm{mg} / 21$ days) of 26-day-old female rats caused a strong decrease in body weight gain, tibial length and growth plate width. The latter was explained by a reduction of the proliferating zone width, which correlated with a reduced number of PCNA-positive cells (not significant)
\end{abstract}

and by a reduction of the hypertrophic zone width. In male rats supplemented with $E_{2}$, similar effects were observed compared with the females. ER $\alpha$ and $\beta$ immunostaining was found predominantly in late proliferating and early hypertrophic chondrocytes. OVX did not affect ER expression but $\mathrm{E}_{2}$ supplementation strongly decreased immunostaining for both ER $\alpha$ and $\beta$ in both sexes. Besides $E_{2}$, desoxyestrone (DE), an activator of nongenomic estrogen-like signaling (ANGEL) and 2-methoxyestradiol $\left(2-\mathrm{MeO}-\mathrm{E}_{2}\right)$, a tissue-selective naturally occurring metabolite of $\mathrm{E}_{2}$, were administered to female and male rats of the same age. Compared with $\mathrm{E}_{2}$, these compounds had less pronounced, though significant, effects on some parameters of longitudinal growth in both sexes, especially on growth plate characteristics. In conclusion, $\mathrm{E}_{2}$ may exert effects on longitudinal growth before and at the onset of sexual maturation, despite very low endogenous serum levels at these stages. There may be a role for nongenomic signaling in body weight gain, tibial length and growth plate width but genomic signaling prevails.

Journal of Endocrinology (2002) 175, 277-288

\section{Introduction}

Recent findings in three male patients, one with an inactivating mutation in the estrogen receptor $\alpha(E R \alpha)$ and two with an aromatase p450 enzyme deficiency, have established that estrogen modulates essential steps regarding growth during puberty, both in boys and girls (Smith et al. 1994, Morishima et al. 1995, Carani et al. 1997). Estrogen can have both direct and indirect effects on the growth plate. It was shown that anti-estrogen lowers growth hormone $(\mathrm{GH})$ secretion, while estrogen augments $\mathrm{GH}$ secretion, especially by increasing the secretory pulse mass (Martha et al. 1992, Metzger \& Kerrigan 1993, Veldhuis 1998). However, patients with Laron syndrome, who are resistant to GH due to a mutation in its receptor, do have a pubertal growth spurt, suggesting GHindependent effects of estrogen as well (Laron et al. 1980). These effects may be mediated in the growth plate itself, since $E R \alpha$ and $\beta$ have been demonstrated in growth plate chondrocytes of several species, including rabbit, rat and human (Kusec et al. 1998, Kennedy et al. 1999, Nilsson et al. 1999, van der Eerden et al. 2001, 2002).

In various mouse and rat models, effects of $17 \beta$-estradiol $\left(\mathrm{E}_{2}\right)$ on longitudinal growth have been described. These 
studies have, however, been mainly performed in animals that were sexually maturing or mature at the start of the experiment and are limited to a few reports. In 7-weekold sexually maturing female rats, ovariectomy (OVX) enhanced longitudinal growth rate (Turner et al. 1994). In contrast, high-dose $\mathrm{E}_{2}(4 \mathrm{mg} / \mathrm{kg}$ per day) strongly reduced tibial growth rate of 2-month-old intact sexually mature male rats (Wakley et al. 1997). In contrast to humans, rats do not fuse their growth plates at the end of sexual maturation, resulting in a continuation of longitudinal growth, albeit at a very low rate. At these stages, $E_{2}$ still inhibited longitudinal growth as has been observed in 3-month-old intact female rats (Tobias et al. 1991).

Concomitant with longitudinal growth, growth plate thickness was increased after OVX, which was primarily explained by induced chondrocyte proliferation (Turner et al. 1994). Likewise, OVX enhanced proliferating cell nuclear antigen (PCNA) protein expression, a marker for cell proliferation, in growth plates from 14-week-old sexually immature rabbits (Tajima et al. 1998). In the same study, serum IGF-I levels were elevated in the OVX animals compared with sham, suggesting an involvement of insulin-like growth factor-I (IGF-I) in the observed increase in chondrocyte proliferation (Tajima et al. 1998). No studies had previously been performed in rats before and at the onset of sexual maturation.

Estrogen actions can be exerted through either a genomic (transcription activation) or a nongenomic pathway, which involves putative membrane-bound receptors and activation of the Src/Shc/ERK signal transduction route (Coleman \& Smith 2001, Kousteni et al. 2001). Until now, it has been unclear to what extent the two pathways contribute to the regulation of longitudinal growth by $E_{2}$. Furthermore, specific estrogen receptor modulators (SERMs) have been described which are known for their tissue selectivity. One of the best-studied SERMs is raloxifene, which prevents postmenopausal bone loss but has minor effects on other tissues, like breast and uterus (Cosman \& Lindsay 1999).

One example enabling distinction between genomic and nongenomic effects of estrogen is the synthetic compound desoxyestrone (DE), which has less than 1\% binding affinity compared with $\mathrm{E}_{2}$ (VanderKuur et al. 1993) and is believed to act exclusively through the nongenomic pathway. It has anti-apoptotic effects in cultured osteoblasts and osteocytes and is able to increase bone mineral density (BMD) and bone strength in both estrogenreplete and estrogen-deficient mice (Manolagas et al. 1999, Kousteni et al. 2001).

Turner \& Evans have recently described a naturally occurring metabolite of $\mathrm{E}_{2}, 2$-methoxyestradiol (2-MeO$\mathrm{E}_{2}$ ), which may well act as a SERM in rats. This compound strongly reduced growth plate thickness in 3-month-old intact female rats due to a reduced chondrocyte proliferation and hypertrophy but no effects were observed on various bone parameters, suggesting a tissue-selective effect of $2-\mathrm{MeO}-\mathrm{E}_{2}$ (Turner \& Evans 2000).

Recently, we demonstrated both ERs in tibial growth plates of female and male rats well before and during sexual maturation (1, 4 and 7 weeks of age), with no apparent regulation of expression by sexual maturation (van der Eerden et al. 2002). Since endogenous levels of estrogen are very low before sexual maturation (Dohler \& Wuttke 1976, Saksena \& Lau 1979), we wondered whether the ERs in the growth plate are functional at this stage. Furthermore, we wanted to know to what extent genomic and nongenomic actions of $\mathrm{E}_{2}$ might contribute to longitudinal growth. To achieve this, 26-day-old rats were either ovariectomized or intact female and male rats of the same age were supplemented with $\mathrm{E}_{2}(0.5 \mathrm{mg} / 21$ days $)$, $\mathrm{DE}$ or $2-\mathrm{MeO}-\mathrm{E}_{2}$ (both $5 \mathrm{mg} / 21$ days). Three weeks later, halfway to sexual maturation, the effects on longitudinal growth were examined. Moreover, we investigated PCNA and ER $\alpha$ and $\beta$ and the relative mRNA expression of IGF-I in the growth plate after OVX, using immunohistochemistry and real-time PCR respectively.

\section{Materials and Methods}

\section{Animals}

Female and male Wistar rats were obtained from Harlan (Broekman Instituut, Someren, The Netherlands). They were kept in a light- and temperature-controlled room (12 h light : $12 \mathrm{~h}$ darkness, $20-22^{\circ} \mathrm{C}$ ) with food and water available ad libitum. Experiments were approved by the local ethics committee for animal experiments.

\section{Experiment 1}

Twenty-four 26-day-old female Wistar rats were ovariectomized by the dorsal approach $(n=11)$ or shamoperated $(n=13)$. During the experiment, body weight was measured weekly and after 3 weeks the animals were killed using a fatal dose of pentobarbital sodium (Nembutal, Sanofi Sante Animale, Maassluis, Netherlands). Rats enter sexual maturation around day 30, and maturation takes about 4 weeks (Tanner 1962). This means that at the start of the experiment rats were still sexually immature, whereas at the end of the experiment they were halfway to sexual maturation. Approximately $50 \%$ of the animals from each experimental group (OVX: $n=5$; SHAM: $n=6)$ were fixed in vivo $(2 \%$ paraformaldehyde in $0 \cdot 1 \mathrm{M}$ phosphate buffer supplemented with $75 \mathrm{mM}$ lysine monohydrochloride and $10 \mathrm{mM} \mathrm{Na}$ periodate) as described previously (van der Eerden et al. 2000). Tibiae were isolated and fixed in the same fixative for $24 \mathrm{~h}$. Next, they were decalcified in 15\% EDTA, including $0.5 \%$ paraformaldehyde for 4 weeks and processed for 
paraffin embedding. Tibiae were cut in halves in a sagittal orientation, processed for paraffin embedding and $5 \mu \mathrm{m}$ sections were cut mid-sagittally. From the other half $(n=6)$, tibiae were collected and the growth plates were carefully excised, avoiding contamination with other cell types. The obtained growth plate material was frozen rapidly and stored at $-80{ }^{\circ} \mathrm{C}$ until use.

\section{Experiment 2}

Twenty-four female and 24 male 26-day-old Wistar rats were implanted with a slow-release pellet (Innovative Research of America, Saratosa, FL, USA) subcutaneously between the scapulae, releasing $0.5 \mathrm{mg}$ of $\mathrm{E}_{2}(n=6), 5 \mathrm{mg}$ of $\mathrm{DE}(n=6)$ or $5 \mathrm{mg}$ of $2-\mathrm{MeO}_{-} \mathrm{E}_{2}(n=6)$ over a 21 -day period. A fourth group received a placebo pellet $(n=6)$. The doses of $\mathrm{DE}$ and 2-MeO- $\mathrm{E}_{2}$ were 10 times higher than that for $\mathrm{E}_{2}$, since they have a lower affinity for the receptor (Merriam et al. 1980, VanderKuur et al. 1993). During the experiment, body weight was measured weekly, and after 3 weeks the animals were killed using a fatal dose of pentobarbital sodium (Nembutal, Sanofi Sante Animale). All animals were fixed in vivo and tibiae were processed as mentioned in the first experiment.

\section{Measurements}

In both experiments, body weight gain (g), tibial bone length $(\mathrm{cm})$, growth plate width (total, proliferating zone and hypertrophic zone: all in $\mathrm{mm}$ ), ratio between proliferating and hypertrophic zone width $(\mathrm{P} / \mathrm{H}$ ratio), the number of chondrocytes and cell diameter $(\mu \mathrm{m})$ in each zone (except DE and 2-MeO-E $\mathrm{E}_{2}$ treated animals), as well as wet weights of thymus $(\mathrm{g})$ were determined. In the second experiment, uterus, testis and liver wet weight (g) were also measured. Values were expressed as means \pm S.D.

\section{PCNA and ER immunohistochemistry}

The immunohistochemical protocol performed for both ERs has been published earlier (van der Eerden et al. 2002). For the detection of PCNA, growth plate sections were incubated in $10 \mathrm{mM}$ citrate buffer $\left(\mathrm{pH} \mathrm{6.0)}\right.$ at $95^{\circ} \mathrm{C}$ for $10 \mathrm{~min}$ followed by $30 \mathrm{~min}$ of cooling down. After blocking, sections were incubated overnight at $4{ }^{\circ} \mathrm{C}$ in $0.5 \%$ blocking buffer with the mouse monoclonal PCNA antibody (Clone PC-01; Calbiochem, San Diego, CA, USA; 1:5000), the rabbit polyclonal ER $\alpha$ antibody (Clone MC-20: Santa Cruz Technologies, Santa Cruz, CA, USA; 1:50) or the goat polyclonal ER $\beta$ antibody (Clone Y-19; Santa Cruz; 1:50). After a number of secondary antibody steps, staining was visualized with AEC $(0 \cdot 2 \mathrm{mg} / \mathrm{ml}$ in acetate buffer pH $5 \cdot 2$ with $0 \cdot 04 \% \mathrm{H}_{2} \mathrm{O}_{2}$; Sigma) for $3 \mathrm{~min}$. After counterstaining with hematoxylin, the sections were embedded in aquamount (BDH, Poole, Dorset, UK). Pictures of growth plate sections from rats in two consecu- tive experiments were taken with a Nikon DXM 1200 digital camera using the same settings and the average number of positive cells in a fixed window was determined using Image-Pro-Plus software (Media Cybernetics Inc., Silver Springs, MD, USA). Next, mean values \pm S.D. were calculated and tested for significance $(P<0 \cdot 05)$ versus control groups, using the Student $t$-test.

\section{$R N A$ isolation and $c D N A$ synthesis}

Total RNA was extracted from growth plate material according to Chomczynski \& Sacchi (1987). Subsequently, RNA samples were treated with RNase-free DNase for $15 \mathrm{~min}$ at $37^{\circ} \mathrm{C}$ to remove residual DNA contamination (Promega, Madison, WI, USA). The concentration of RNA was determined spectrophotometrically.

One microgram of RNA was denatured $(10 \mathrm{~min}$ at $70{ }^{\circ} \mathrm{C}$ followed by $5 \mathrm{~min}$ on ice) and reverse transcribed in a $20 \mu \mathrm{l}$ reaction containing first strand buffer $(75 \mathrm{mM} \mathrm{KCl}$, $3 \mathrm{mM} \mathrm{MgCl}_{2}$ and $50 \mathrm{mM}$ Tris- $\left.\mathrm{HCl}, \mathrm{pH} 8 \cdot 3\right), 5 \mathrm{mM}$ DTT, $0.375 \mathrm{mM}$ dNTPs, $200 \mathrm{ng}$ of random hexanucleotides (all from Life Technologies, Breda, the Netherlands), 1 unit of RNasin (Promega) and 2.5 units of M-MLV reverse transcriptase (Life Technologies) at $37^{\circ} \mathrm{C}$ for $60 \mathrm{~min}$ and denatured again at $70{ }^{\circ} \mathrm{C}$ for $10 \mathrm{~min}$. A second addition of 1 unit of RNasin and 2.5 units of M-MLV reverse transcriptase was performed in each tube and the reaction was allowed to proceed at $37^{\circ} \mathrm{C}$ for $30 \mathrm{~min}$ followed by inactivation of the enzymes by incubation at $70{ }^{\circ} \mathrm{C}$ for $10 \mathrm{~min}$. Samples were diluted and stored until use at $-20^{\circ} \mathrm{C}$.

\section{Real-time PCR}

Three microliters of cDNA were amplified in a total volume of $25 \mu \mathrm{l}$ containing $1^{\star}$ buffer A, $3.5 \mathrm{mM} \mathrm{MgCl}$ (Applied Biosystems, Foster City, CA, USA), $0 \cdot 2 \mathrm{mM}$ dNTPs (Roche, Basel, Switzerland), $50 \mathrm{pmol} / \mathrm{ml}$ of the forward and reverse primer (Eurogentec, Seraing, Belgium), $5 \mathrm{pmol} / \mathrm{ml}$ probe and $5 \mathrm{U} / \mathrm{ml}$ AmpliTaq Gold (Applied Biosystems).

The probe sequences for the household gene, rat porphobilinogen deaminase (PBGD; 5'-CCA-GCTGAC-TCT-TCC-GGG-TGC-CCA-C-3') and rat IGF-I (5'-ACA-GGC-TAT-GGC-TCC-AGC-ATTCGG-A-3') were labeled with the reporter dye FAM on the $5^{\prime}$ and with the quencher dye TAMRA on the $3^{\prime}$ site. The primer sequences for rat PBGD were: forward (5'-ATG-TCC-GGT-AAC-GGC-GGC-3') and reverse (5'-CAA-GGT-TTT-CAG-CAT-CGC-TAC-CA-3'); and for rat IGF-I: forward (5'-TCA-GTT-CGT-GTGTGG-ACC-AAG-3') and reverse (5'-TCA-CAGCTC-CGG-AAG-CAA-C-3'). The amplified products for PBGD and IGF-I were 135 and $117 \mathrm{bp}$ long respectively. 


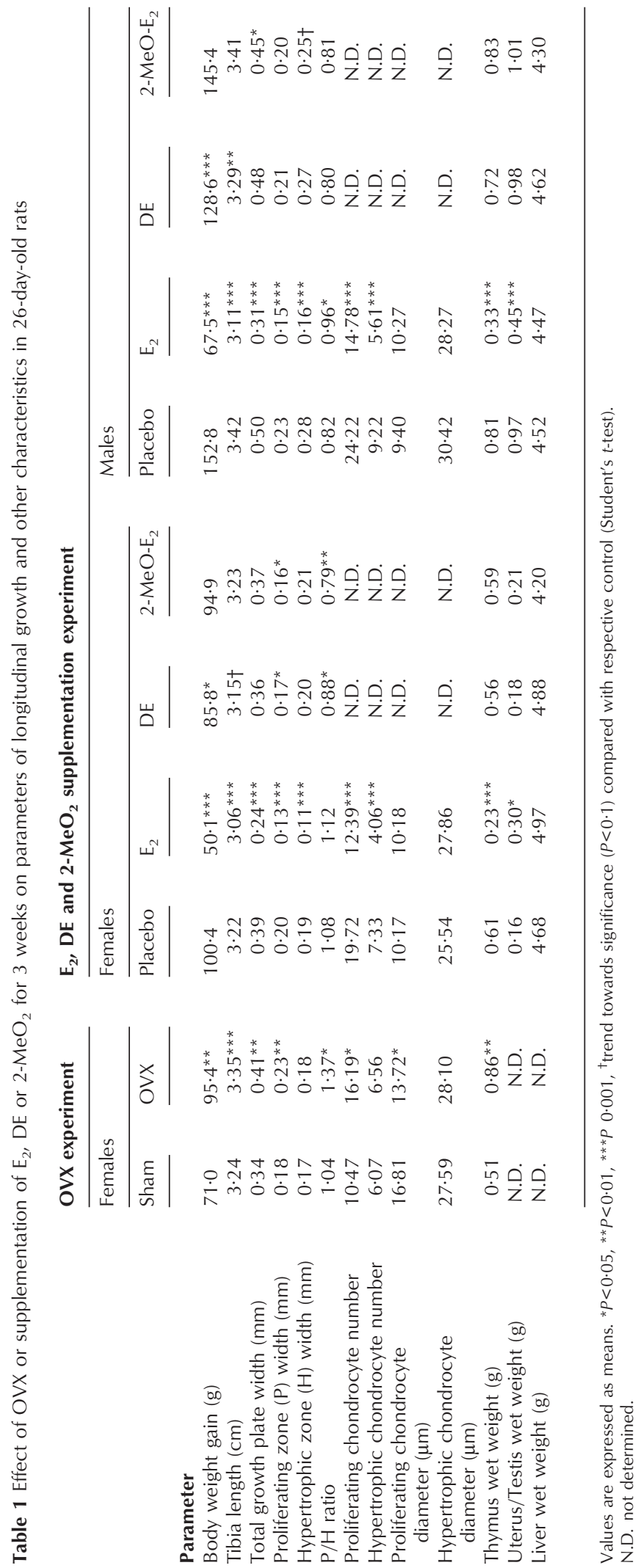




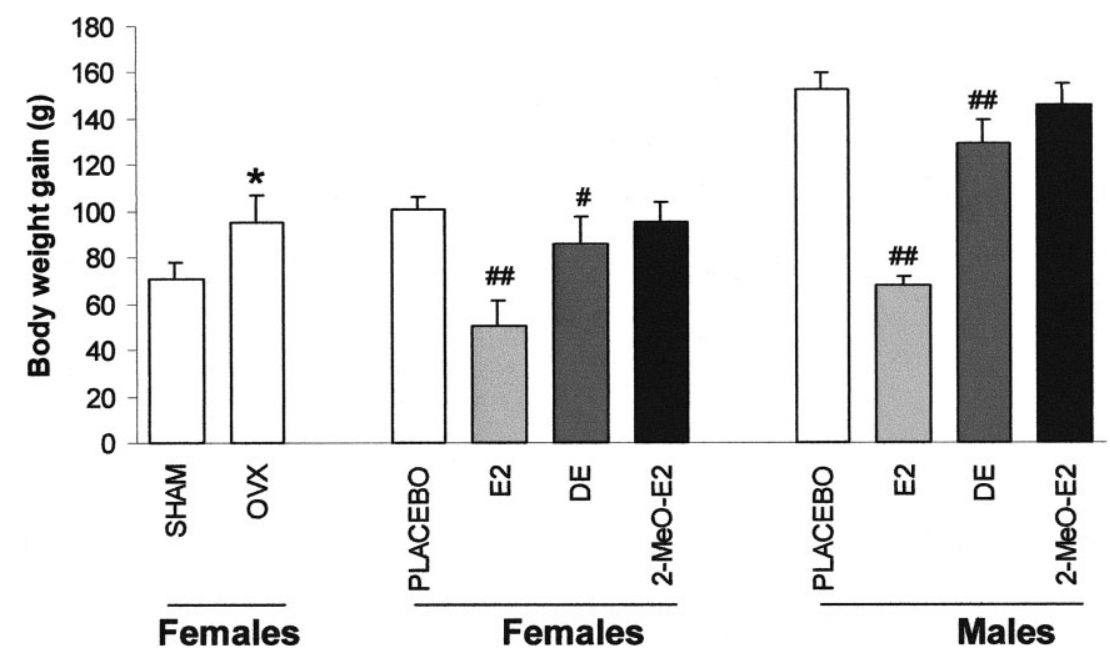

Figure 1 Effects of OVX and estrogen supplementation on body weight gain. Body weight gain was determined 3 weeks after OVX or $E_{2}$, DE or 2-MeO- $E_{2}$ supplementation of 26-day-old female and male rats. Values are given as means \pm S.D. ${ }^{*} P<0 \cdot 05$ compared with sham; ${ }^{\#} P<0.05$ and ${ }^{\# \#} P<0.001$ compared with placebo.

For standardization, both PBGD and IGF-I primer sets were tested with different amounts of cDNA to determine the suitable amount of cDNA to be used in the quantitative analysis. The Taqman reaction included 40 thermal cycles consisting of $15 \mathrm{~s}$ at $95{ }^{\circ} \mathrm{C}$ and $1 \mathrm{~min}$ at $60{ }^{\circ} \mathrm{C}$ and was run on an ABI Prism 7700 Sequence Detector (Applied Biosystems). Finally, the Ct value (number of cycles to reach threshold value) was determined for all samples and mean values \pm S.D. were calculated for each experimental group.

\section{Results}

\section{OVX experiment}

We performed OVX in 26-day-old female rats and assessed several parameters concerning longitudinal growth 3 weeks later, which are summarized in Table 1. At the start of the experiment, the rats were still sexually immature and 3 weeks later, they were halfway to sexual maturation. OVX caused significant increases in body weight gain (Fig. 1). When examining longitudinal growth, both tibial length (Fig. 2A) and growth plate width (Fig. 2B) increased significantly compared with sham-operated rats. The wider growth plates in OVX animals were associated with an increased proliferating zone width, while the width of the hypertrophic zone was unaltered. The ratio between the width of the proliferating and the hypertrophic zone $(\mathrm{P} / \mathrm{H}$ ratio) increased in the OVX animals (Table 1). The increase in the proliferating zone was associated with a significant increase in cell number with a decreased cell diameter compared with sham. Cell number and diameter were unchanged in the hypertrophic zone (Table 1). Representative HE-stained sections (Fig. 2C) from an OVX (b) and sham-operated (a) rat illustrate the results in Fig. 2B.

To further address the increased proliferating zone width after OVX, PCNA immunohistochemistry and real-time PCR for IGF-I on cDNA from growth plate preparations were performed. Based on an analysis of two mid-sagittal growth plate sections from the sham $(n=5)$ and OVX group $(n=7)$, the number of PCNA-positive cells significantly increased after OVX compared with SHAM (Fig. 3A; $266 \pm 37$ vs $181 \pm 49$ cells; $P=0 \cdot 019$ ). A representative picture of a PCNA-stained growth plate section of a sham-operated and an OVX rat is shown in Fig. 3B ( $\mathrm{a}$ and $\mathrm{b}$ respectively). PCNA immunostaining was primarily found in the proliferating zone, although some positive cells were detected in the hypertrophic zone. Using real-time PCR on cDNAs from dissected growth plates $(n=6)$, amounts of cDNA were adjusted for expression of the housekeeping gene PBGD. The difference between the expression levels of IGF-I and PBGD (Ct value) in each rat for the OVX versus SHAM rats did not reach significance $(0.62 \pm 0.61$ vs $0.36 \pm 0.79$; $P=0.53$ ), which was underscored by a near identical IGF-I expression level (OVX/SHAM ratio $=0 \cdot 83$ ). Thymus wet weight of OVX rats was significantly increased compared with sham.

\section{Estrogen supplementation experiment}

As a mirror experiment, either $\mathrm{E}_{2}(0 \cdot 5 \mathrm{mg} / 21$ days), $\mathrm{DE}$ or $2-\mathrm{MeO}-\mathrm{E}_{2}$ (both $5 \mathrm{mg} / 21$ days) was supplemented to 26 -day-old female and male rats for 3 weeks $(n=6)$. The effects of estrogen supplementation are summarized in 

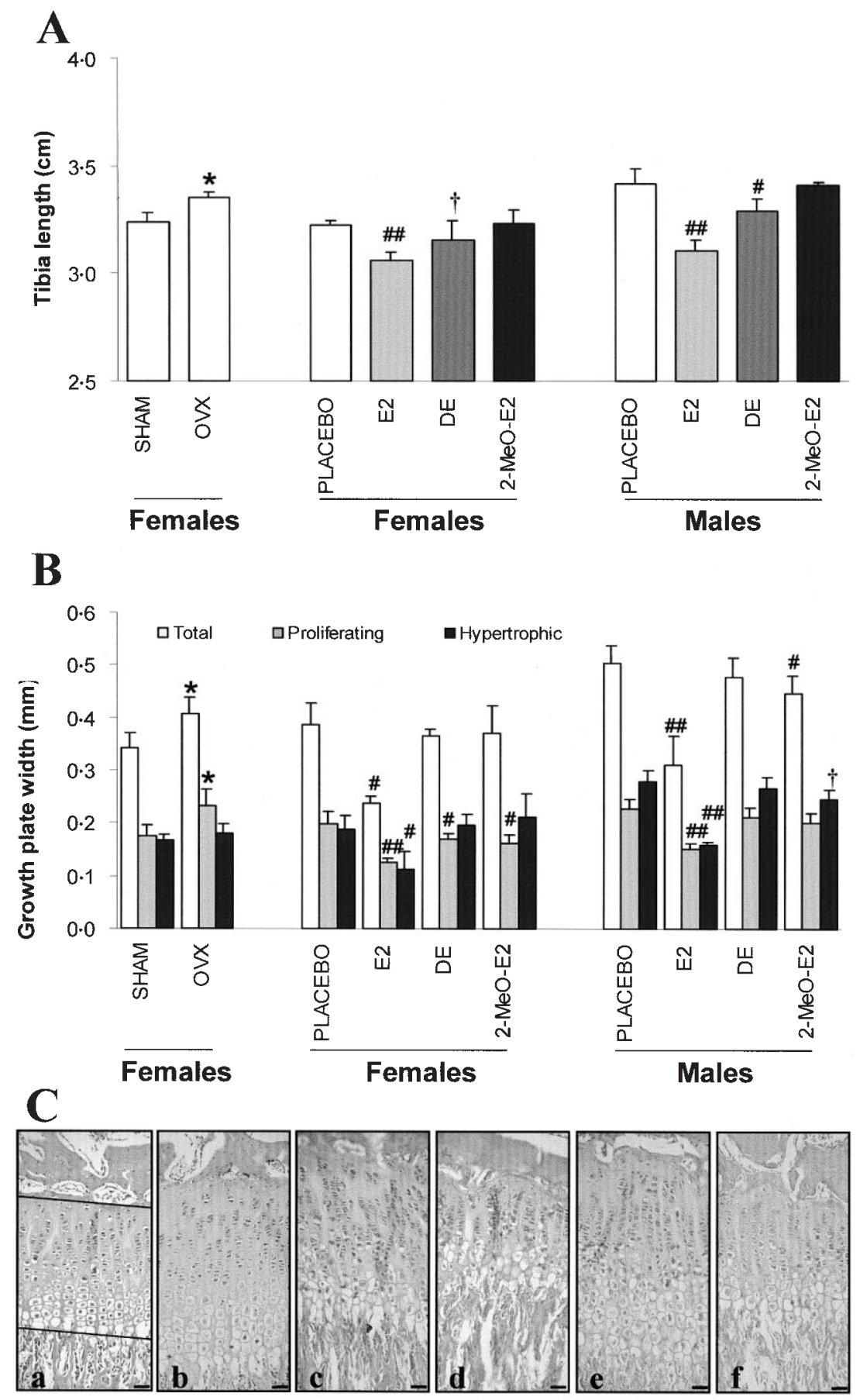

Figure 2 Effects of OVX and estrogen supplementation on tibia length and growth plate width. (A) Tibia length was measured 3 weeks after OVX or $\mathrm{E}_{2}$, DE or 2-MeO- $\mathrm{E}_{2}$ supplementation of 26-day-old female and male rats. (B) Total, proliferating zone and hypertrophic zone widths were determined 3 weeks after $\mathrm{OVX}$ or $\mathrm{E}_{2}$, DE or 2-MeO- $\mathrm{E}_{2}$ supplementation of 26-day-old female and male rats. (C) Representative growth plate images of a sham-operated (a) and OVX rat (b) as well as female and male placebo controls (c and e respectively) and $E_{2}$-supplemented ( $d$ and $f$ respectively) rats. The added lines in (a) indicate the borderlines between the growth plate and the epi- and metaphysis and the transition between proliferating and hypertrophic chondrocytes and were used to determine the width of the proliferating and hypertrophic zones. Bars represent $50 \mu \mathrm{m}$. Values are given as means \pm S.D. ${ }^{*} P<0 \cdot 05$ compared with sham; ${ }^{\#} P<0 \cdot 05$, $\# \#<0 \cdot 001$ and ${ }^{\dagger}$ trend towards significance $(P<0 \cdot 1)$ compared with placebo. 

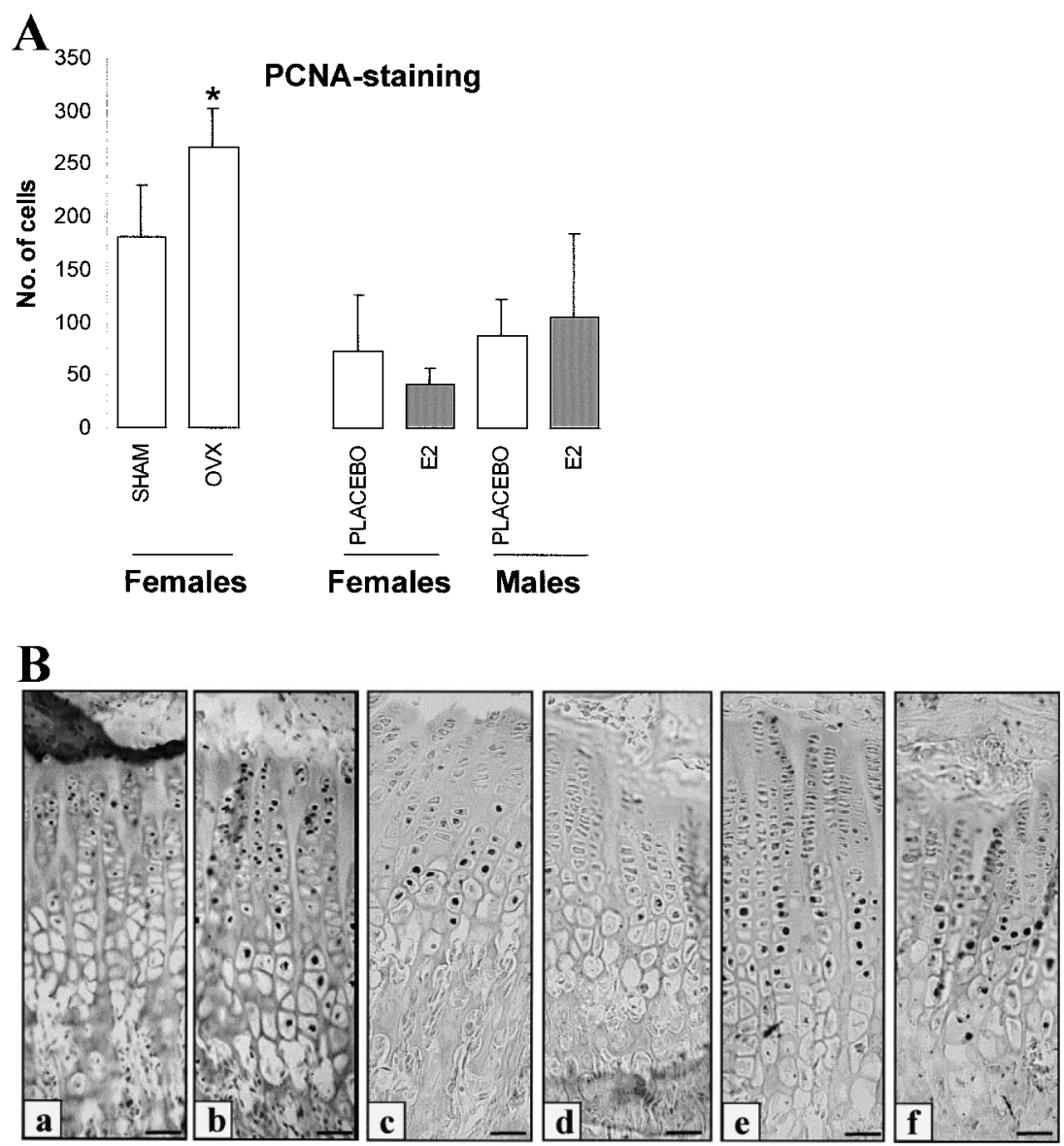

Figure 3 Effects of OVX on PCNA staining in the growth plate. (A) After immunohistochemistry for PCNA, the number of positively stained chondrocytes was determined 3 weeks after OVX of 26-day-old female rats and in $E_{2}$-supplemented female and male rats by image analysis. Values are given as means \pm S.D. ${ }^{\star} P<0 \cdot 05$ compared with SHAM. (B) Representative growth plate images of a sham-operated (a), OVX rat (b), female placebo (c), female with $E_{2}$ supplementation (d), male placebo (e) and male with $E_{2}$ supplementation (f). Note the increased number of immunopositive nuclei in the growth plate of the OVX rat, predominantly in the proliferating zone (b) compared with sham (a). Bars represent $50 \mu \mathrm{m}$.

Table 1. Compared with placebo rats, administration of $\mathrm{E}_{2}$ via slow-release pellets caused a significant decrease in body weight gain in females and males (Fig. 1). Longitudinal growth was affected by $\mathrm{E}_{2}$, exemplified by a significant decrease in tibial length (Fig. 2A) and growth plate width (Fig. 2B) in both genders. In females, the reduced width of the growth plate was caused by a significant decrease of both the proliferating zone and the hypertrophic zone (Fig. 2B), with an unaltered $\mathrm{P} / \mathrm{H}$ ratio compared with placebo. In males, however, the reduction of the hypertrophic zone width was more severe than of the proliferating zone, leading to significantly higher $\mathrm{P} / \mathrm{H}$ ratio compared with controls (Table 1). In both sexes, the decrease in width of the proliferating and hypertrophic zone was associated with a significant decrease in cell number with unchanged cell diameter compared with placebo (Table 1). Representative HE-stained growth plate sections are shown in Fig. 2C (panels $\mathrm{c}-\mathrm{f}$ ). $\mathrm{E}_{2}$ tended to decrease the number of PCNA immunopositive cells in female (Fig. 3A; $40 \cdot 8$ vs $72 \cdot 5$ cells and Fig. 3B: $c$ and d) but not in male (Fig. 3A: $105 \cdot 2$ vs 88.0 cells and Fig. 3B: e and f) rats $(n=6)$. In most of the growth plates studied, staining for PCNA seemed to be dominant in pre-hypertrophic and even hypertrophic chondrocytes, especially in the males (Fig. 3B: $c-f$ ). Due to large inter-animal variation in expression levels, the results did not reach significance.

Estrogen supplementation decreased thymus wet weight in females and males and increased uterus or decreased testis wet weight respectively. No effect was observed on liver wet weight (Table 1). 

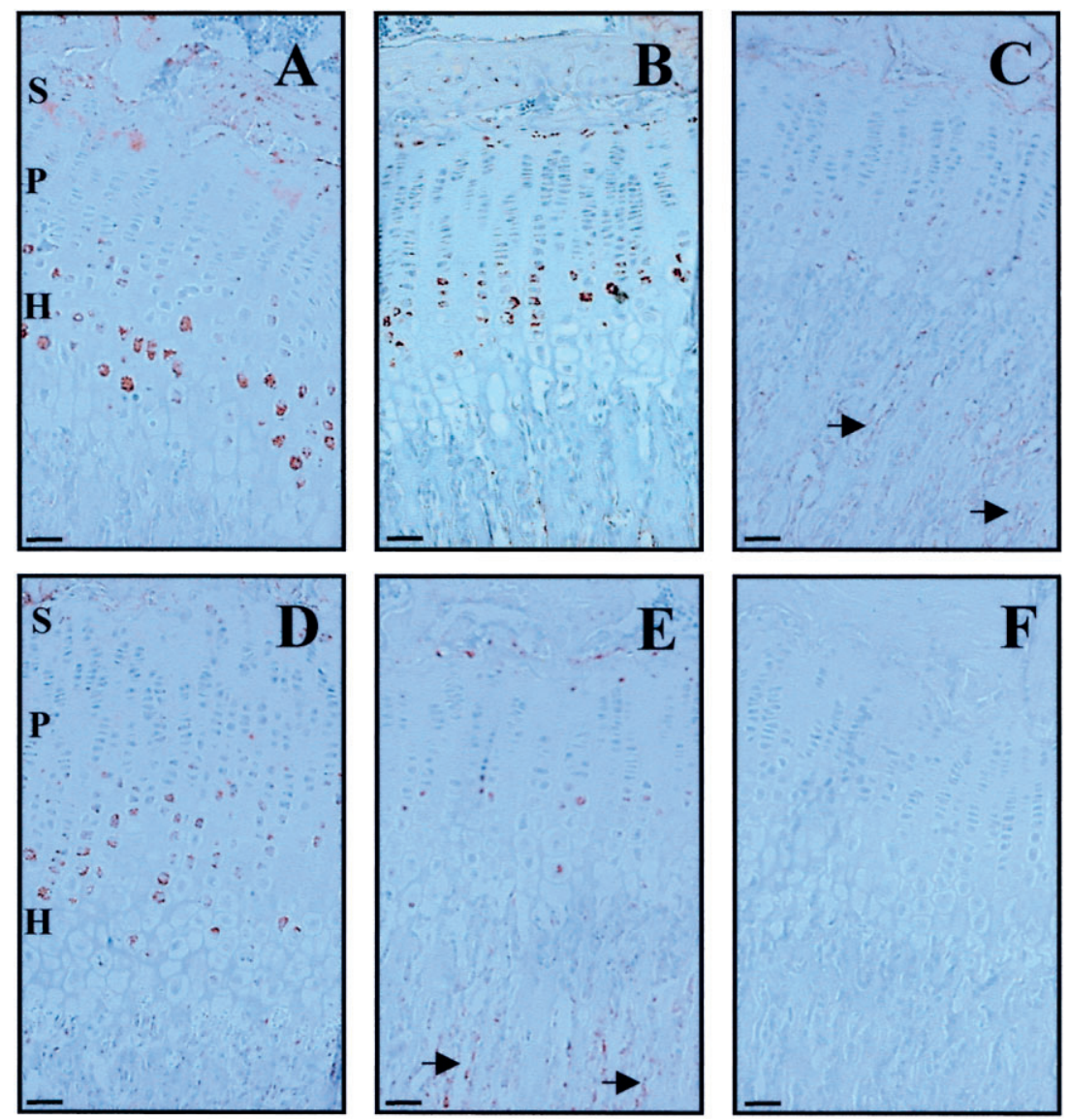

Figure 4 Effects of $O V X$ and $E_{2}$ supplementation on $E R \alpha$ and $\beta$ staining in the growth plate. Growth plate sections from the different animal groups were stained for ER $\alpha$ or $\beta$. Positive staining was predominantly found in late proliferating $(\mathrm{P})$ and early hypertrophic $(\mathrm{H})$ chondrocytes. No differences in staining intensity were seen between the female placebo (A), OVX (B) or male placebo (D). $E_{2}$ reduced $E R \alpha$ and $\beta$ staining in females (C) and males (E) in the growth plate, whereas it increased the expression in osteoblasts of the primary spongiosum (see arrows in $\mathrm{C}$ and $\mathrm{E}$ ). Omission of the first antibody ( $\mathrm{F}$ ) resulted in absence of staining. S, stem cells. Bars represent $50 \mu \mathrm{m}$.

Supplementation of DE led to a number of significant effects (Table 1), albeit to a much lesser extent than $E_{2}$. Body weight gain significantly decreased compared with placebo in both sexes (Fig. 1). Furthermore, in females there was a trend towards significance concerning decrease of tibial length (Fig. 2A). Despite an unaltered total growth plate width, the width of the proliferating zone was significantly reduced leading to a lower $\mathrm{P} / \mathrm{H}$ ratio compared with placebo. In DE-supplemented males, tibial length was significantly reduced (Fig. 2A), whereas at the level of the growth plate no changes were evident.

When 2-MeO-E $\mathrm{E}_{2}$ was supplemented, no effects were seen on body weight gain (Fig. 1) and tibia length (Fig. 2A) in females and males. However, at the level of the growth plate, females had a significantly reduced proliferating zone width (Fig. 2B), leading to a reduced $\mathrm{P} / \mathrm{H}$ ratio (Table 1 ), whereas in males the significantly reduced total growth plate width seemed to be associated primarily with a decreased width of the hypertrophic zone, which showed a trend towards significance (Fig. 2B). Due to the small changes in growth plate width, we did not determine the number of cells in the different zones in the $\mathrm{DE}$ and 2-MeO-E $\mathrm{E}_{2}$ supplemented rats. DE and $2-\mathrm{MeO}-\mathrm{E}_{2}$ had no effect on thymus, uterus, testis or liver wet weight compared with placebo controls.

\section{ER $\alpha$ and $\beta$ expression in growth plates}

Previously, we have demonstrated ER $\alpha$ and $\beta$ protein expression in the growth plate of the rat (van der Eerden et al. 2002). To study whether the expression of the ERs is regulated by OVX or $E_{2}$, supplementation immunohistochemistry was performed. Positive staining for ER $\alpha$ and $\beta$ was predominantly detected in late proliferating and 
early hypertrophic chondrocytes. No differences in staining intensity were seen between the sham (data not shown), placebo (Fig. 4A and D) or OVX rats (Fig. 4B). In contrast, $\mathrm{E}_{2}$ supplementation caused a downregulation of $\operatorname{ER} \alpha$ and $\beta$ staining in growth plates of females and males (Fig. $4 \mathrm{C}$ and $\mathrm{E}$ respectively). In contrast, $\mathrm{E}_{2}$ supplementation increased $\mathrm{ER} \alpha$ and $\beta$ staining in osteoblastic cells of the primary spongiosum (Fig. 4C and E). Negative controls, including pre-incubation with a corresponding peptide and omission of the first antibody (Fig. 4F), resulted in absence of staining.

\section{Discussion}

We recently found that in female and male rats before sexual maturation (1 and 4 weeks of age), both ER $\alpha$ and ER $\beta$ were expressed in the tibial growth plate at the mRNA and protein level, implying that this tissue may be responsive to estrogens before sexual maturation (van der Eerden et al. 2002). To assess this, we either ovariectomized or supplemented female and male rats with $\mathrm{E}_{2}, \mathrm{DE}$ or $2-\mathrm{MeO}-\mathrm{E}_{2}$ at 26 days of age and analyzed several parameters of longitudinal growth and chondrocyte proliferation 3 weeks later. Rats usually enter sexual maturation around day 30, and maturation takes approximately 4 weeks (Tanner 1962), implying that rats were still sexually immature at the start of our experiments, while they were halfway to sexual maturation when the experiments were terminated.

OVX of 26-day-old rats caused strong increments in body weight gain, tibia length and growth plate width over a 3-week period compared with sham. The increased growth plate width was explained by a widening of the proliferating zone, which was associated with an increased cell number as well as an increased number of PCNA immunopositive cells. In contrast to OVX, $\mathrm{E}_{2}$ supplementation in female rats of the same age resulted in opposite effects: a dramatically reduced body weight gain, tibial length and growth plate width, the latter being caused by both a reduction in the proliferating zone and hypertrophic zone width. Concomitant with the reduced proliferating zone, $E_{2}$ tended to decrease the number of PCNApositive chondrocytes as well, although this did not reach significance. In male rats, the parameters of longitudinal growth were similarly decreased compared with females. However, no reduction of PCNA-positive cells was observed.

Turner and co-workers demonstrated increased longitudinal growth rates in ovariectomized 7-week-old sexually maturing rats, whereas subsequent estrogen supplementation reversed this (Turner et al. 1994). The lowest effective dose of $\mathrm{E}_{2}$ was lower than in our study (1.5 vs $23 \mu \mathrm{g} /$ day), but these rats were previously ovariectomized (Turner et al. 1994). Moreover, two reports in which intact 3-month-old female and 2-month-old sexually mature male rats received approximately $200 \mu \mathrm{g} /$ day $\mathrm{E}_{2}$, demonstrated a substantial decrease in longitudinal growth (Tobias et al. 1991, Wakley et al. 1997). Our data extend previous data, claiming that as well as in sexually maturing or mature rats, $E_{2}$ also inhibits longitudinal growth before and at the onset of sexual maturation. OVX of 26-day-old rats results in enhanced parameters of longitudinal growth, despite very low endogenous estrogen levels, suggesting that even in this period, $E_{2}$ may have an inhibitory effect on growth.

The change in tibial length after OVX or $\mathrm{E}_{2}$ supplementation coincided with changes in growth plate width. Estrogen removal in females caused an increase in proliferating zone width and therefore total growth plate width, whereas estrogen supplementation reduced the width of both the proliferating and hypertrophic zone in both genders. Moreover, the increased width of the proliferating zone after OVX paralleled the increased PCNA staining, whereas $E_{2}$ supplementation did not significantly alter the number of immunopositive cells in the growth plate. In males, the immunostaining in the hypertrophic zone was quite high, especially in the $\mathrm{E}_{2^{-}}$ treated rats, which contributed to an absence of an effect of $E_{2}$ on PCNA staining compared with placebo. In the $\mathrm{E}_{2}$-supplementation experiment, and to a lesser extent in the OVX experiment, PCNA-positive nuclei were abundantly observed in the pre- and hypertrophic zone. In a study by Aizawa and co-workers, the same phenomenon has been described in rabbit growth plates (Aizawa et al. 1997). It appears that subtle changes in the fixation procedure as well as the fact that chondrocytes have a long G1 phase in relation to the $\mathrm{S}, \mathrm{G} 2$ and $\mathrm{M}$ phase contribute to the relatively high number of PCNA-positive hypertrophic chondrocytes (Aizawa et al. 1997). In addition, we speculate that $\mathrm{E}_{2}$ may have a sexually dimorphic effect on the cell cycle G1 phase duration in chondrocytes (Leung \& Potter 1987, Takahashi \& Noumura 1987).

The inhibitory effect of $E_{2}$ on chondrocyte proliferation is well established. It has been shown that thymidine uptake is reduced following $E_{2}$ administration in sexually maturing rats and PCNA staining is increased after OVX in sexually immature rabbits (Turner et al. 1994, Tajima et al. 1998). In the latter study, besides increased PCNA staining, serum IGF-I levels were increased, suggesting that the proliferating effect of OVX was caused in part by serum IGF-I (Tajima et al. 1998). In our study, we did not determine serum levels of IGF-I, since a dramatic decrease of total serum IGF-I did not affect body weight and longitudinal growth in liver-specific IGF-I knockout mice (Yakar et al. 1999). Instead, local effects of IGF-I seemed more important for longitudinal bone growth. Therefore, we quantified the amount of IGF-I mRNA in preparations from tibial growth plates using real-time PCR. We found no difference in relative IGF-I mRNA levels between OVX and sham. This suggests that the effects of $E_{2}$ status on chondrocyte proliferation cannot be explained by 
influencing local IGF-I expression. However, we cannot exclude changes in expression levels of other members of the IGF family (IGF-II, IGF-I and II receptors and IGF binding proteins) in the growth plate caused by $\mathrm{E}_{2}$.

Removal of $E_{2}$ has no effect on the width of the hypertrophic zone, whereas $\mathrm{E}_{2}$ administration reduces both proliferating and hypertrophic zone widths. The reduced width of the hypertrophic zone may be a direct effect of $E_{2}$ itself but it may also be secondary to an effect on chondrocyte proliferation.

It was reported that estrogen reduces matrix synthesis, which has been shown to contribute to an age-related decline in longitudinal growth (Hunziker 1988). This may be in line with our study, since OVX decreased the cell diameter in the proliferating zone, despite an increase in its width, indicating that matrix synthesis is downregulated when estrogen is deficient. In contrast, it has been shown that $\mathrm{E}_{2}$ stimulates ${ }^{35} \mathrm{~S}$ uptake by chondrocytes, implying increased chondrocyte differentiation (Corvol et al. 1987, Blanchard et al. 1991). An explanation for a reduced width of the hypertrophic zone could be that estrogen causes the rate of apoptosis or vascular invasion to exceed the rate of cartilage matrix synthesis (Turner \& Evans 2000).

We recently demonstrated that ER expression levels were relatively unaffected by endogenous estrogen levels (van der Eerden et al. 2002). In this study, we found that OVX did not affect ER $\alpha$ or $\beta$ expression. However, treatment with a medium dose of $\mathrm{E}_{2}$ caused a reduction in the expression levels of both receptors in male and female rats. From these findings, one may conclude that a substantial rise in endogenous estrogen levels is apparently required to elicit alterations in receptor expression in the rat growth plate. Interestingly, the raised $\mathrm{E}_{2}$ levels increased receptor expression in osteoblasts of the primary spongiosum. This suggests that $\mathrm{E}_{2}$ can either down- or upregulate the expression of its own receptor, depending on the cell type.

From our data we cannot exclude effects of $E_{2}$ on the somatotropic axis. It has been shown that estrogen augments GH secretion, especially by increasing the secretory pulse mass (Veldhuis 1998, Martha et al. 1992). In addition, anti-estrogens lower the basal GH secretion (Metzger \& Kerrigan 1993). However, direct effects are also likely to occur since the $\mathrm{P} / \mathrm{H}$ ratio increases strongly following OVX, whereas in dwarf rats $(\mathrm{dw} / \mathrm{dw})$, which have reduced $\mathrm{GH}$ levels to $5 \%$ of normal, the $\mathrm{P} / \mathrm{H}$ ratio is similar to that in normal rats and this ratio is not affected by subsequent GH treatment (Gevers et al. 1996). These results suggest that $E_{2}$ inhibits longitudinal bone growth most likely by direct effects on chondrocyte proliferation and differentiation in female and male rats before sexual maturation. Since $\mathrm{E}_{2}$ removal causes such dramatic effects on longitudinal growth, it seems evident that despite its low endogenous levels, $\mathrm{E}_{2}$ may play an important role in controlling longitudinal growth in these animals at this stage.
In analogy with $\mathrm{E}_{2}$ supplementation, we have used the synthetic compound DE, which, based on its lower binding affinity compared with $\mathrm{E}_{2}$, was administered at a dose 10 times higher than $\mathrm{E}_{2}$ ( $5 \mathrm{mg} / 21$ days) (VanderKuur et al. 1993). Despite the fact that supplementation of $\mathrm{DE}$ after OVX would result in more pronounced effects, we chose intact rats, since this mimics better the situation when it would be used clinically. DE was recently recognized as an activator of nongenomic estrogen-like signaling (ANGEL) and exhibits anti-apoptotic effects on osteoblasts and osteocytes in vitro (Kousteni et al. 2001). Moreover, DE increases BMD and bone strength in both estrogen-replete and estrogen-deficient mice (Manolagas et al. 1999).

Although to a lesser extent than $\mathrm{E}_{2}, \mathrm{DE}$ decreased body weight gain in both sexes, tibial length (trend towards significance in females) and growth plate width (not significant in males). In addition, females had a decreased proliferating zone width combined with a reduced $\mathrm{P} / \mathrm{H}$ ratio. However, despite a 10 times higher dose for $\mathrm{DE}$ compared with $\mathrm{E}_{2}$, no effects were found on wet weights of thymus, uterus and testis, whereas $\mathrm{E}_{2}$ severely affected these organs. This suggests that in the classical estrogen target tissues genomic effects are most important, whereas in bone and cartilage genomic and nongenomic pathways mediate the effect of estrogen. These results imply a role for genomic and nongenomic signaling in the regulation of body weight gain, tibia length and growth plate width, although genomic signaling prevails.

In addition to $\mathrm{DE}, 2-\mathrm{MeO}-\mathrm{E}_{2}$ was administered at a similar dose used for DE, since this naturally occurring metabolite of $\mathrm{E}_{2}$ has a very low binding affinity compared with $\mathrm{E}_{2}$ (Merriam et al. 1980). Our 2-MeO-E 2 supplementation experiment was comparable to that by Turner \& Evans (2000) using intact rats, but there were some differences. The rats in our study were sexually immature at the start of the experiment, whereas the female rats used by Turner \& Evans were sexually mature (3 months). Moreover, we used slow-release pellets with a relatively low dose $(230 \mu \mathrm{g} /$ day $)$, establishing relatively constant levels during the experiment, while Turner administered $2-\mathrm{MeO}-\mathrm{E}_{2}$ orally $(20 \mathrm{mg} /$ day), not knowing precisely what amount the gastro-intestinal tract absorbs. Furthermore Turner \& Evans demonstrated dramatically reduced longitudinal bone growth and growth plate width in the 3 -month-old sexually mature intact female rats. Interestingly, no effects were found on radial bone growth and cancellous bone turnover or on uterus wet weight (Turner \& Evans 2000). Our results were less pronounced but a significant growth plate width reduction was observed in male rats, which was primarily explained by a reduction of the hypertrophic zone width (trend towards significance). Growth plate width in females did not alter but the proliferating zone width was significantly reduced and, subsequently, the $\mathrm{P} / \mathrm{H}$ ratio. We found no effects of $2-\mathrm{MeO}-\mathrm{E}_{2}$ on body weight gain, tibial length and wet 
weights of thymus, uterus/testis or liver. From these results, we may conclude that, although not as pronounced as in an earlier study, effects of $2-\mathrm{MeO}-\mathrm{E}_{2}$ seem to be limited to the regulation of growth plate parameters only, suggesting that it might be used as a SERM in the future.

In conclusion, $\mathrm{E}_{2}$ may exert effects on longitudinal growth before and at the onset of sexual maturation, despite very low serum levels at these stages. There may be a role for nongenomic signaling in body weight gain, tibial length and growth plate width, explaining some of the effects on longitudinal growth, but genomic signaling prevails. DE administration in ovariectomized rats should provide more evidence on the relative contribution of genomic and nongenomic signaling in longitudinal growth.

\section{Acknowledgement}

Financial support by Ferring BV, The Netherlands, is gratefully acknowledged.

\section{References}

Aizawa T, Kokubun S \& Tanaka Y 1997 Apoptosis and proliferation of growth plate chondrocytes in rabbits. Journal of Bone and Joint Surgery 79B 483-486.

Blanchard O, Tsagris L, Rappaport R, Duval-Beaupere G \& Corvol M 1991 Age-dependent responsiveness of rabbit and human cartilage cells to sex steroids in vitro. Journal of Steroid Biochemistry and Molecular Biology 40 711-716.

Carani C, Qin K, Simoni M, Faustini-Fustini M, Serpente S, Boyd J, Korach KS \& Simpson ER 1997 Effect of testosterone and estradiol in a man with aromatase deficiency. New England Journal of Medicine 337 91-95.

Chomczynski P \& Sacchi N 1987 Single-step method of RNA isolation by acid guanidinium thiocyanate-phenol-chloroform extraction. Analytical Biochemistry 162 156-159.

Coleman KM \& Smith CL 2001 Intracellular signaling pathways: nongenomic actions of estrogens and ligand-independent activation of estrogen receptors. Frontiers in Bioscience 6 D1379-D1391.

Corvol MT, Carrascosa A, Tsagris L, Blanchard O \& Rappaport R 1987 Evidence for a direct in vitro action of sex steroids on rabbit cartilage cells during skeletal growth: influence of age and sex. Endocrinology 120 1422-1429.

Cosman F \& Lindsay R 1999 Selective estrogen receptor modulators: clinical spectrum. Endocrine Reviews 20 418-434.

Dohler KD \& Wuttke W 1976 Circadian fluctuations of serum hormone levels in prepubertal male and female rats. Acta Endocrinologica 83 269-279.

van der Eerden BCJ, Karperien M, Gevers EF, Lowik CW \& Wit JM 2000 Expression of Indian hedgehog, parathyroid hormone-related protein, and their receptors in the postnatal growth plate of the rat: evidence for a locally acting growth restraining feedback loop after birth. Journal of Bone and Mineral Research 15 1045-1055.

van der Eerden BCJ, Karperien M \& Wit JM 2001 The estrogen receptor in the growth plate: implications for pubertal growth. Journal of Pediatric Endocrinology and Metabolism 14 1527-1533.

van der Eerden BCJ, Gevers EF, Lowik CW, Karperien M \& Wit JM 2002 Expression of estrogen receptor $\alpha$ and $\beta$ in the epiphyseal plate of the rat. Bone $30478-485$.
Gevers EF, Milne J, Robinson IC \& Loveridge N 1996 Single cell enzyme activity and proliferation in the growth plate: effects of growth hormone. Journal of Bone and Mineral Research 11 $1103-1111$.

Hunziker EB 1988 Growth plate structure and function. Pathology and Immunopathology Research 7 9-13.

Kennedy J, Baris C, Hoyland JA, Selby PL, Freemont AJ \& Braidman IP 1999 Immunofluorescent localization of estrogen receptor-alpha in growth plates of rabbits, but not in rats, at sexual maturity. Bone 24 9-16.

Kousteni S, Bellido T, Plotkin LI, O'Brien CA, Bodenner DL, Han L, Han K, DiGregorio GB, Katzenellenbogen JA, Katzenellenbogen BS, Roberson PK, Weinstein RS, Jilka RL \& Manolagas SC 2001 Nongenotropic, sex-nonspecific signaling through the estrogen or androgen receptors: dissociation from transcriptional activity. Cell $104719-730$.

Kusec V, Virdi AS, Prince R \& Triffitt JT 1998 Localization of estrogen receptor-alpha in human and rabbit skeletal tissues. Journal of Clinical Endocrinology and Metabolism 83 2421-2428.

Laron Z, Sarel R \& Pertzelan A 1980 Puberty in Laron type dwarfism. European Journal of Pediatrics 134 79-83.

Leung BS \& Potter AH 1987 Mode of estrogen action on cell proliferation in CAMA-1 cells: II. Sensitivity of G1 phase population. Journal of Cellular Biochemistry 34 213-225.

Manolagas SC, Weinstein RS, Bellido T, Bodenner DL, Jilka, RL \& Parfitt AM 1999 Activators of non-genomic estrogen-like signaling (ANGELS): a novel class of small molecules with bone anabolic properties. Journal of Bone and Mineral Research 14 S180.

Martha PM Jr, Gorman KM, Blizzard RM, Rogol AD \& Veldhuis JD 1992 Endogenous growth hormone secretion and clearance rates in normal boys, as determined by deconvolution analysis: relationship to age, pubertal status, and body mass. Journal of Clinical Endocrinology and Metabolism 74 336-344.

Merriam GR, MacLusky NJ, Picard MK \& Naftolin F 1980 Comparative properties of the catechol estrogens, I: methylation by catechol-O-methyltransferase and binding to cytosol estrogen receptors. Steroids $361-11$.

Metzger DL \& Kerrigan JR 1993 Androgen receptor blockade with flutamide enhances growth hormone secretion in late pubertal males: evidence for independent actions of estrogen and androgen. Journal of Clinical Endocrinology and Metabolism 76 1147-1152.

Morishima A, Grumbach MM, Simpson ER, Fisher C \& Qin K 1995 Aromatase deficiency in male and female siblings caused by a novel mutation and the physiological role of estrogens. Journal of Clinical Endocrinology and Metabolism 80 3689-3698.

Nilsson LO, Boman A, Savendahl L, Grigelioniene G, Ohlsson C, Ritzen EM \& Wroblewski J 1999 Demonstration of estrogen receptor-beta immunoreactivity in human growth plate cartilage. Journal of Clinical Endocrinology and Metabolism 84 370-373.

Saksena SK \& Lau IF 1979 Variations in serum androgens, estrogens, progestins, gonadotropins and prolactin levels in male rats from prepubertal to advanced age. Experimental Aging Research $\mathbf{5}$ 179-194.

Smith EP, Boyd J, Frank GR, Takahashi H, Cohen RM, Specker B, Williams TC, Lubahn DB \& Korach KS 1994 Estrogen resistance caused by a mutation in the estrogen-receptor gene in a man. New England Journal of Medicine 331 1056-1060.

Tajima Y, Yokose S, Kawasaki M \& Takuma T 1998 Ovariectomy causes cell proliferation and matrix synthesis in the growth plate cartilage of the adult rat. Histochemical Journal 30 467-472.

Takahashi MM \& Noumura T 1987 Sexually dimorphic and laterally asymmetric development of the embryonic duck syrinx: effect of estrogen on in vitro cell proliferation and chondrogenesis. Developmental Biology 121 417-422.

Tanner JM 1962 The adolescent spurt in animals. In Growth at Adolescence, pp 223-239. Ed. CC Thomas. Oxford: Blackwell. 
Tobias JH, Chow J, Colston KW \& Chambers TJ 1991 High concentrations of 17 beta-estradiol stimulate trabecular bone formation in adult female rats. Endocrinology 128 408-412.

Turner RT \& Evans GL 2000 2-Methoxyestradiol inhibits longitudinal bone growth in normal female rats. Calcified Tissue International 66 465-469.

Turner RT, Evans GL \& Wakley GK 1994 Reduced chondroclast differentiation results in increased cancellous bone volume in estrogen-treated growing rats. Endocrinology 134 461-466.

VanderKuur JA, Hafner MS, Christman JK \& Brooks SC 1993 Effects of estradiol-17 beta analogues on activation of estrogen response element regulated chloramphenicol acetyltransferase expression. Biochemistry 32 7016-7021.
Veldhuis JD 1998 Neuroendocrine control of pulsatile growth hormone release in the human: relationship with gender. Growth Hormones and IGF Research 8 (Suppl B) 49-59.

Wakley GK, Evans GL \& Turner RT 1997 Short-term effects of high dose estrogen on tibiae of growing male rats. Calcified Tissue International 60 37-42.

Yakar S, Liu JL, Stannard B, Butler A, Accili D, Sauer B \& Leroith D 1999 Normal growth and development in the absence of hepatic insulin-like growth factor I. PNAS 96 7324-7329.

Received 26 June 2002

Accepted 3 July 2002 